\title{
A Framework for Measuring the Interoperability of Geo-Ontologies
}

\author{
Frederico Fonseca $^{a} \quad$ Gilberto Câmara $^{b}$ Antonio Miguel Monteiro $^{\mathrm{b}}$ \\ ${ }^{a}$ College of Information Sciences and Technology, Pennsylvania State University \\ University Park, PA 16802, USA \\ email: fredfonseca@ist.psu.edu \\ ${ }^{\mathrm{b}}$ Image Processing Division (DPI), National Institute for Space Research (INPE) \\ Av dos Astronautas, 1758, São José dos Campos SP 12227-001, Brazil \\ email: $\{$ gilberto, miguel $\}$ @dpi.inpe.br
}

Keywords: ontologies, interoperability, measurement

Short title: Measuring Interoperability of Geo-ontologies

Author for correspondence:

Frederico Fonseca

College of Information Sciences and Technology

The Pennsylvania State University

307E IST Building

University Park, PA 16802

Office: (814) 865-6460

Fax: (814) 865-6426

E-mail: fredfonseca@ist.psu.edu 


\title{
A Framework for Measuring the Interoperability of Geo-Ontologies
}

\begin{abstract}
Interoperability is a crucial problem for geographic information systems. The transfer of data and models between different systems requires the ability to set up a correspondence between concepts in one system to concepts in the other. Concept matching is helped by ontologies. However, the challenge of making ontologies themselves interoperable continues. In other words, given two geo-ontologies, the basic question is: to which degree are these two geo-ontologies interoperable? In this paper, we consider that a geo-ontology describes things that can be assigned to locations on the surface of the Earth and relations between these things. A geo-ontology has concepts that correspond to physical and social phenomena in the real world. We suggest a classification of these concepts based on their use for describing geo-objects. We present a basic set of concepts for a geographical ontology, based on descriptions of the physical world and of the social reality. We also present a framework for measuring the degree of interoperability between geo-ontologies. We consider that this problem is a special case of Bernstein's model management algebra for metadata descriptions. We propose to use a matching operator for measuring interoperability between ontologies. The proposed framework provides a first basis for computational tools that allow a more precise response to problem of ontology interoperability.
\end{abstract}

Keywords: interoperability, geo-ontologies, measurement 


\section{Introduction}

Interoperability is defined by the Open GIS consortium as the "capability to communicate, execute programs, or transfer data among various functional units in a manner that requires the user to have little or no knowledge of the unique characteristics of those units" (OpenGIS, 1996). The use of ontologies improves interoperability among different information systems in general (Mena, Kashyap, Sheth, \& Illarramendi, 1996; Wiederhold, 1994) and in geographical information systems specifically (Fonseca \& Egenhofer, 1999; M. Kavouras \& Kokla, 2002). The subject of ontology is an important field of research in geographical information science (Y. A. Bishr \& Kuhn, 2000; Bittner \& Winter, 1999; Câmara, Monteiro, Paiva, \& Souza, 2000; Fonseca, Egenhofer, Agouris, \& Câmara, 2002; Frank, 1997; Frank, 2001; Marinos Kavouras, Kokla, \& Tomai, 2005; Werner Kuhn, 2001; David Mark, 1993; Raubal \& Kuhn, 2004; Rodríguez, Egenhofer, \& Rugg, 1999; Smith \& Mark, 1998). The use of ontologies for modeling of geographical entities aims at capturing shared conceptualizations of specific user communities and thus improve interoperability among different geographical databases (Smith \& Mark, 1998). However, the quest for making ontologies themselves interoperable continue (Arumugam, Sheth, \& Arpinar, 2002; Heflin \& Hendler, 2000).

The general basis for ontology is the emphasis on shared vocabularies and on properties that hold in all situations. Ontologies are content theories about the sorts of objects, properties of objects, and possible relations between objects in a specified domain of knowledge (Chandrasekaran, Josephson, \& Benjamins, 1999). Thus, informally defined, "ontologies are agreements about shared conceptualizations."

However, most approaches to ontological characterization focus on concrete proposals for tools and techniques for building ontologies, such as the W3C Semantic Web (BernersLee, Hendler, \& Lassila, 2001). Frank \& Raubal (1999) argue that the formalization of spatial relations in geographic space is crucial for further advances in the standardization and interoperability of GIS. They review methods for the formal description of spatial relations and create specifications and methods to formalize and describe image schemata.

Here, we propose a method for computing a measurement of the degree of interoperability between two geo-ontologies. The method is illustrated by applying it to ontologies based on 
different land cover classification schemes. The measurement is based on the model management algebra for metadata descriptions created by Bernstein (2003). In other words, given two geo-ontologies, the basic question to be examined is to which degree are these two geo-ontologies interoperable?

This paper is an initial attempt to address this question. For the purposes of this paper only, we consider that a geo-ontology belongs to the simplest case mentioned by Guarino, namely that "an ontology describes a hierarchy of concepts related by subsumption relationships". Therefore, we opted for a hierarchical structure of geo-ontologies as shown in our examples in sections 3 and 4, although we recognize that geo-ontologies can be much more complex than that.

The rest of the paper is organized as follows. In section 2, we give an overview of the current research on the use of ontologies to implement interoperability. Section 3 discusses the special characteristics on an ontology that makes it be called a geo-ontology. In section 4, we present a framework for measuring the interoperability of geo-ontologies. In section 5 we give our conclusions and propose further work in the area.

\section{Ontology-Based Interoperability}

The literature shows many proposals for the integration of information, ranging from federated databases with schema integration (A. Sheth \& Larson, 1990) and the use of object orientation (Kent, 1993; Papakonstantinou, Garcia-Molina, \& Widom, 1995), to mediators (Wiederhold, 1991) and ontologies (Guarino, 1998; Wiederhold, 1994). Semantic heterogeneity is the disagreement about the meaning, interpretation, or intended use of data (A. Sheth \& Larson, 1990). The new generation of information systems should be able to handle semantic heterogeneity in making use of the amount of information available with the arrival of the Internet and distributed computing (Amit Sheth, 1999). The semantics of information integration is getting more attention from the research geographic information science community (Y. Bishr, 1997; Câmara, Souza, Freitas, \& Monteiro, 1999; Gahegan, 1999; Harvey, 1999; Kashyap \& Sheth, 1996; W. Kuhn, 1994; Andrea Rodríguez \& Max Egenhofer, 2003; Amit Sheth, 1999; Worboys \& Deen, 1991). The support and use of multiple ontologies should be a basic feature of modern information systems if they want to support semantics in the integration of information. Ontologies that 
capture the semantics of information can be represented in a formal language and be used to store the related metadata enabling a semantic approach to information integration.

\subsection{Ontology and ontologies}

From Gruber's (1992) definition that "an ontology is an explicit specification of a conceptualization", Guarino (1998) created a refined distinction between an ontology and a conceptualization. Guarino starts the discussion saying that a conceptualization is "a set of conceptual relations defined on a domain space" and that it is important to "focus on the meaning of these relations, independently of a state of affairs" (Guarino, 1998). He says that in a conceptualization we are interested, for instance, in the meaning of the relation 'above' instead of being concerned that in this particular state of affairs object A is above object B. After clarifying what a conceptualization is, he says that "an ontology is a logical theory accounting for the intended meaning of a formal vocabulary, i.e. its ontological commitment to a particular conceptualization of the world. The intended models of a logical language using such a vocabulary are constrained by its ontological commitment. An ontology indirectly reflects this commitment (and the underlying conceptualization) by approximating these intended models". Smith (2003) says that in the current context of research on information sharing, an ontology is seen as a dictionary of terms expressed in a canonical syntax. In this use it is implied that ontology is a common vocabulary shared by different information systems communities.

Smith gives a definition of an information system ontology: "an ontology is a formal theory within which not only definitions but also a supporting framework of axioms is included (perhaps the axioms themselves provide implicit definitions of the terms involved)" (Smith, 2003). The definition of terms for spatial relations can be studied by analyzing the entailments of statements. Frank \& Raubal (1999) derive spatial relations from image schemata using language. For instance, the concept of path can be derived from the expression "You can drive from Baden to Vienna, and back in the evening." (p.79) and the concept of detour can be derived of "The way from Vienna to Budapest through Sopron is a detour. The direct route goes through Györ." (p.80). 


\subsection{Ontologies, Agreements, and Geographical-Information Interoperability}

The interoperability of geographic information (Michael Goodchild, Egenhofer, Fegeas,

\& Kottman, 1999; Vckovski, 1998) has gained in importance because of the new possibilities arising from the interconnected world and the increasing availability of geographic information. New information originates from new geographical information systems and also from new and sophisticated data collection technologies. It is necessary to find innovative ways to make sense of the huge amount of information available today.

What kinds of agreement can be reached among people? Limited-scope agreements can be made within small communities. Later, these agreements can be expanded to reach larger communities. When these broad agreements occur, part of the original meaning is lost, or at least some level of detail is lost (Fonseca, Egenhofer, Davis, \& Câmara, 2002). For instance, inside a community of biology scholars, a specific lake in the state of New Mexico is the habitat for a specific species and, therefore, it can have a special concept or name to refer to it such as aquatic habitat. Nonetheless, it is still a lake, and when a biologist is working at a more general level it is considered as a lake and not as an aquatic habitat only. At this higher level it is more likely that this real-world entity-lake-can find a match with a similar concept in another community. So the biologist and some member of another community can exchange information about lakes. The information will be more general than when the lake was seen as an aquatic habitat.

The agreements are represented as ontologies, one for each subject area (Wiederhold, 1994). Ontologies are crucial for information exchange and they can serve as the embodiment of a consensus reached by a professional community (Farquhar, Fikes, \& Rice, 1996). Some authors (Kashyap \& Sheth, 1996) consider that sharing the same ontology is a pre-condition to information sharing and integration. In this case, there should be an ontological commitment revealing the agreement between the generic user querying the database and the database administrator. Other authors suggest an alternative to an explicit ontological commitment. One common solution is the derivation of a global schema to overcome the absence of a common shared ontology. Bergamaschi et al. (1998) implemented this solution using description logic. Along the same lines, Rodríguez et al. (1999) developed a similarity assessment among ontologies using a feature-matching process and semantic distance calculations. 


\subsection{Model Management and Interoperability}

Model Management is a new approach to metadata management that can be applied to problems such as schema integration and schema evolution. It considers models and mappings between models as objects and offers operators to compare and combine these objects (P. Bernstein, 2003; P. A. Bernstein, 2001).

In order to understand how Model Management, which was created to manage schemas, can be applied to the measurement of interoperability between Geo-Ontologies, we need to consider two points. First, we need to consider ontologies as models. Ontologies and conceptual schemas definitely belong to two different epistemic levels. Nevertheless they are part of a continuum that starts from the conceptualizations of GIS designers and users, later expressed in informal and formal languages, and goes to the creation of conceptual schemas and the subsequent representation of facts in a spatial database. Second, because Model Management is an approach to metadata, it uses only the description of data and not the data itself. Therefore, we need to consider ontologies as containing only metadata and not data. While the research in conceptual modeling argue for the creation of more generic models, the research on ontologies sometimes (wrongly in our point of view) go to specifics such as having instances of classes within ontologies. As McGuinness (2003) points out, "some classification schemes only include class names while others include ground individual content". The recording of instances or ground content should be done by the GIS itself under the guidance of the conceptual schema. The recording of facts belongs to a different epistemic level. Ontologies definitely should not include instances of its concepts.

In a traditional Model Management system, models and mappings are syntactic structures. In order to make the problem computationally tractable it is necessary to have limited expressiveness. Bernstein's Model Management opted to add semantic processing through an extension mechanism that uses an inferencing engine. This engine is able to manipulate formulas in a mathematical system (P. Bernstein, 2003; P. A. Bernstein, 2001).

In a similar work, Kuhn (1997) describes an algebraic mapping between data models. His main focus is information loss which is defined based on the number of operations that a source system can apply on data and a target system cannot. Goodchild (1997) considers 
this definition useful but counterintuitive because it misses some cases such as when a receiving system does not have an operation (information loss occurs) and later this system returns the same data to a system which has the operations (the original information is restored).

\subsection{Ontology Mappings}

Kalfoglou \& Schorlemmer (2003), in an extensive survey, define ontology mappings as "the task of relating the vocabulary of two ontologies that share the same domain of discourse in such a way that the mathematical structure of ontological signatures and their intended interpretations, as specified by the ontological axioms, are respected." Wache et al. (2001) suggest a classification for the main approaches in inter-ontology mapping. They call Defined Mappings the approach in which the user creates the rules and mediators to generate specific mapping between concepts in two ontologies. While this approach provides great flexibility it does not preserve semantics. KRAFT (Preece et al., 2000) is an example for this case. The second type of approach is called Lexical Relations. An example is OBSERVER (Kashyap \& Sheth, 1996; Mena, Kashyap, Illarramendi, \& Sheth, 1998; Mena et al., 1996), an architecture for query processing in global information systems. OBSERVER focuses on information content and semantics and employs a loosely-coupled approach to match different vocabularies used to describe similar information across domains. The next approach examined by Wache et al. is called Top-Level Grounding. In this approach all the mappings go through a top-level ontology. The fact that the mappings go through concepts in a different ontology leads to the drawback of not having direct

mappings between the ontologies of interest. Finally there is Semantic Correspondences, an approach favored by Wache (1999). This approach relies on a common vocabulary in the definition of concepts.

Noy has two reviews of ontology merging. In Noy \& Musen (2002) an interactive ontology-merging tool called PROMPT is evaluated and criteria to group the different tools that are available for ontology merging are introduced. In Noy (2004) semantic integration is discussed in three dimensions: Mapping Discovery that is about how to find similarities between concepts; Declarative Formal Representations of Mappings which is about how to represent the mappings in order to enable reasoning between them, and finally the third 
dimension, Reasoning with Mappings, which is how to reason once the mappings are established.

\section{Geo-Ontologies}

"What is special about spatial?" (Anselin, 1989; Egenhofer, 1993) or what is special about geo-ontologies? A geo-ontology has to provide a description of geographical entities, which can be conceptualized in two different views of the world (Couclelis, 1992; M. Goodchild, 1992). The field view considers spatial data to be a set of continuous distributions. The object view conceives the world as occupied by discrete, identifiable entities. Representing geographic entities-either constructed features or natural variation on the surface of the Earth-is a complex task. As Smith \& Mark (1998) put it, these entities are not merely located in space, they are tied intrinsically to space. They take from space some of its structural characteristics, such as mereological, topological, geometrical properties. A geo-ontology is different from other ontologies because topology and partwhole relations play a major role in the geographic domain. Geographic objects can be connected or contiguous, scattered or separated, closed or open. They are typically complex and have constituent parts (Smith \& Mark, 1998). The topological and containment relations between objects have led to the use of mereology (Husserl, 1970), which describes the relation between parts and wholes. For a review of mereology see Simons (1987) and Casati \& Varzi (1999). Smith (1995) introduced mereotopology, which extends the theory of mereology with topological methods. A theory that combines geometry and mereology using a 1st-order sublanguage is introduce by Bennet (2001). Bennet's theory of RegionBased Geometry (RBG) provides a secure ontological foundation for theories of spatial information.

\subsection{What is a Geo-Ontology?}

A geo-ontology has two basic types of concepts: (a) concepts that correspond to physical phenomena in the real world; (b) concepts that correspond to features of the world that we create to represent social and institutional constructs. We call the first type of concepts physical concepts and the second type, social concepts (Figure 1). 
Based on John Searle's book, "The Construction of Social Reality" (1995), Smith and Searle (2003) have an interesting discussion on what are social objects and if they exist. Smith says that

"Searle tells us what social objects are by giving us an account of the way the two levels are linked together, via the formula $X$ counts as $Y$ in context $C$. His ontology of social reality thus rests on three components:

1. certain physical objects

2. certain cognitive acts or states in virtue of which such physical objects acquire certain special sorts of functions

3. these functions themselves

4. contexts in which the given cognitive acts or states are effective." (p. 286)

Searle does not agree with Smith's interpretation. He thinks that

" a social fact is simply any case of collective intentionality involving two or more animals. Institutional facts are more interesting, because they involve a deontic component, and with that deontic component comes the requirement of language." (p.304)

Searle is concerned with institutional reality, which is a special case of social reality.

It is important to note that both result from human conventions. As discussed in the literature (Frank \& Mark, 1991; David Mark \& Egenhofer, 1994; D. Mark, Smith, \& Tversky, 1999; Smith \& Mark, 2003) the description of physical features may vary according to cultural and social conventions but nevertheless they do not represent social conventions, they represent variations on the surface of the Earth.

The physical concepts can be further subdivided into:

- Concepts that are associated with individual geographic objects, each of which has a clearly defined boundary such as qualitative differentiations or spatial discontinuities in the physical world. These are equivalent to the notion of bona fide objects (Smith \& Mark, 1998). Examples: lake, mountain. 
- Concepts that are assumed to be continuous in space (fields). Examples: temperature, slope, pollution, population density.

The social and institutional concepts that can be further subdivided into:

- Concepts describing individual objects created by institutional and legal conventions. These are equivalent to the notion of fiat objects of Smith and Mark (1998). Examples: parcel, borough.

- Concepts which are assumed to be continuous over space and represent socially agreed conventions. Examples: social exclusion, infant mortality, homicide rate, human development.

\begin{tabular}{|c|c|c|}
\cline { 2 - 3 } \multicolumn{1}{c|}{} & Physical Reality & Social Reality \\
\hline Bounded & Bona fide objects (e.g., mountain) & Fiat objects (e.g., parcel) \\
\hline Continuous & Physical fields (e.g., temperature) & $\begin{array}{c}\text { Social distributions (e.g., human } \\
\text { development) }\end{array}$ \\
\hline
\end{tabular}

Figure 1 - Basic components of a geo-ontology

An alternative way of describing a geo-ontology has been proposed by Frank (2001). He proposes a coordinated set of tiers of ontology. His first tier, Tier 0 , assumes an external reality consisting of a space-time set of continuous fields. The next tier, Tier 1, is composed of the measurements of this reality by humans and their instruments. Tier 2 consists of objects which are formed by humans based on measurements. Tier 3 is the set of objects of social reality constructed by agreements and contracts, following Searle (1995). The last tier, Tier 4, is composed on subjective concepts about space. As an example, consider a rural geographical area. A farmer may use a GPS instrument to collect a set of coordinates. This set of coordinates may correspond to a 'closed polygon', a concept that belongs to Tier 1. In Tier 2, these set of coordinates may be assigned to a "spatial object", which distinguishes the enclosed land area. In Tier 3, this enclosed land area may be called a "farm", and will be assigned an owner who has certain legal rights. Finally, in Tier 4, this farm may be called "home" by the person who lives there. 
Frank's (2001) view of tiers of ontology is similar to our distinction between physical reality and social reality. Entities of the physical reality belong to Frank's Tier 2 ("objects with properties") and entities of the social reality belong to Frank's Tier 3 ("social reality"). The main difference between our work and Frank's is that we are concerned with interoperability between ontologies. We consider concepts that are typically part of geographical databases. Thus, we do not consider concepts that are part of Frank's Tier 0, Tier 1 and Tier 4. Frank's Tier 0 (the external reality) is an implicit assumption in geoontologies. Measurements (Frank's Tier 1) are entities whose existence is required to capture different aspects of external reality. Interoperability of measurements is outside the scope of this work. The interested reader should read Kuhn (2003) and Chrisman (1999). Finally, subjective entities of Tier 4 (such as 'home', and 'sacred area') are also outside the scope of this work. The interested reader on subjective concepts of space should see Fonseca and Martin (2004).

After Smith \& Mark (1998), who wrote that "our cognitive acts are directed towards spatial objects in the world", we consider that concepts in a geo-ontology are directed towards spatial objects in the world. Based on this discussion, we assume that a geoontology is organized as a hierarchy where the root concept is termed "geo object". The root concept is specialized into two classes which correspond to the main types of geographic concepts: those related to continuous phenomena (fields) and to individual objects. The former class is further specialized into concepts associated to physical fields and those associated to socially-constructed fields. The latter class is further specialized into bona fide concepts and fiat concepts. This structure is shown in Figure 2. 


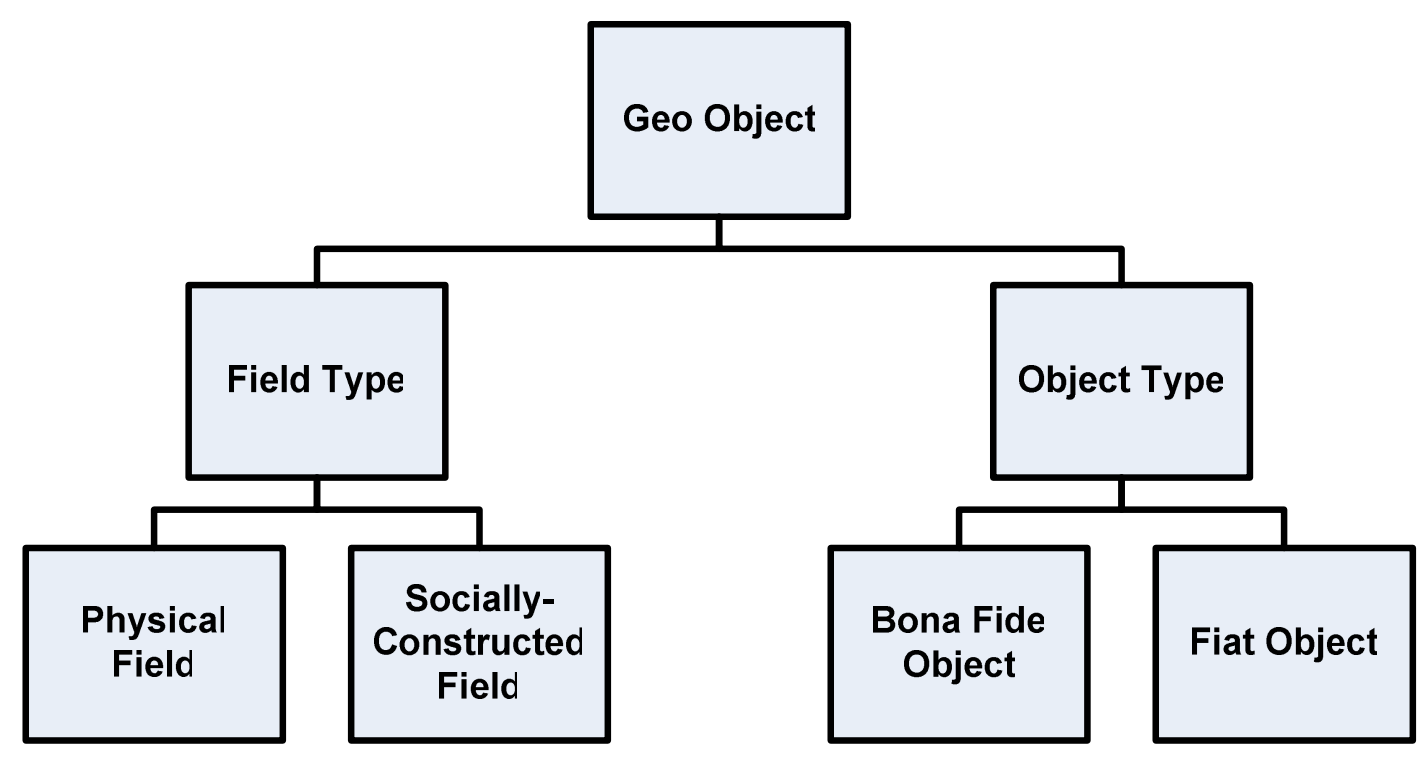

Figure 2 - Top-level hierarchy for a geo-ontology

\section{Using Model Management to Measure Interoperability}

This section presents a framework for measuring the interoperability between geoontologies. We consider that the problem of determining the interoperability between two geo-ontologies is a special case of Bernstein's (2003) Model Management Algebra for metadata descriptions. Bernstein proposes a generic set of operators that abstracts from the traditional object-at-a-time conversion techniques and treats models as abstractions that can be manipulated as single entities. For dealing with interoperability, we use the Match operator from the functions that Bernstein proposed in his Model Management Algebra. The Match operator takes two models and returns two sets of tuples that reflect the similarity and generalization relationships that exist between the concepts of the two ontologies.

In this paper we are not concerned either with how this function is created or with its detailed operation on particular elements in their domains. Other research deals with these matters and justifies particular choices (Bench-Capon \& Malcolm, 1999; Bench-Capon, Malcolm, \& Shave, 2003; A. Rodríguez \& Max Egenhofer, 2003). Instead, the focus here is on how this function can be used to define the degree of interoperability between geoontologies. All the definitions below assume that the function Match exists and is applicable to geo-ontologies. 


\subsection{Ontologies as Models}

In order to apply the concepts of model management to geo-ontologies, we must first provide a definition of ontologies such that it satisfies the technical requirements for model representation (P. Bernstein, 2003). To deal with ontologies as models, each geo-ontology should refer to a single application domain and should have the following properties:

- A geo-ontology consists of a set of concepts;

- Concepts can be related to other concepts by means of relations that include similarity, generalization, and subsumption;

- A geo-ontology consists of a single hierarchy. Starting from a root concept, concepts are placed on the hierarchy according to their specialization relation, which is assumed to be unique.

\subsection{The Match Operator between Ontologies}

In order to compare two ontologies, we use the Match operator, which compares concepts in the ontologies, following Bernstein (2003). The basic idea is to take the most specialized concepts in the first ontology (all leaf-nodes of the ontology tree) and try to find a similar concept in the second ontology. We consider that matching the leaf-nodes of both ontologies is a sufficient condition for ontology matching, since in hierarchical ontologies as those used in this paper, each geo-object is mapped to only one concept. Given a concept in the first ontology, the Match operator proceeds via the following steps:

(a) The SIM (similarity) algorithm tries to identify similar concepts on ontologies. Given a concept $\mathrm{C}_{1}$ of $\mathrm{O}_{1}$, SIM finds a similar concept $\mathrm{C}_{2}$ of $\mathrm{O}_{2}$. The conditions for this mapping may be complex (P. Bernstein, 2003). For a survey of for semantic matching proposals using ontologies see Noy (2004). In general, the retrieval operation will produce a list of possible concepts that can be ranked based on their parts, attributes and relationships (A. Rodríguez \& Max Egenhofer, 2003).

(b) Should step (a) fail to produce a satisfactory result, the GEN algorithm tries to identify the concept in the second ontology that is most closely related to it by generalization. A possible implementation of the GEN algorithm would be as follows: (1) given a concept $c_{1}$ of $O_{1}$ that has no similar match on $O_{2}$, use the 
concept $d_{1}$ that is the generalization of $c_{1}$; (2) try to find a similar concept to $d_{1}$ in $\mathrm{O}_{2}$. If a similar concept is found $\left(\mathrm{d}_{2}\right)$, then $\mathrm{d}_{2}$ is a generalization of $c_{1}$ in ontology $\mathrm{O}_{2}$.

The concept of similarity may be based on equality of names or definitions, or may be based on subjective attribution. The same assumption holds for the notions of generalization. The Match function produces two subsets as a result:

- $\operatorname{Sim}\left(\mathrm{O}_{1}, \mathrm{O}_{2}\right)$ : The similarity subset $\operatorname{Sim}\left(\mathrm{O}_{1}, \mathrm{O}_{2}\right)$ of $\mathrm{O}_{1}$ in relation to $\mathrm{O}_{2}$ is the set of all tuples $\left\langle\mathrm{O}_{1}, \mathrm{O}_{2}>\right.$ such that the concept $\mathrm{O}_{2}$ in $\mathrm{O}_{2}$ is similar to the concept $\mathrm{O}_{1}$ in $\mathrm{O}_{1}$.

- Gen $\left(\mathrm{O}_{1}, \mathrm{O}_{2}\right)$ : The generalization subset Gen $\left(\mathrm{O}_{1}, \mathrm{O}_{2}\right)$ of $\mathrm{O}_{1}$ in relation to $\mathrm{O}_{2}$ is the set of all tuples $<\mathrm{O}_{1}, \mathrm{O}_{2}>$ such that the concept $\mathrm{O}_{2}$ in $\mathrm{O}_{2}$ is a generalization of the concept $\mathrm{o}_{1}$ in $\mathrm{O}_{1}$.

The properties of the geo-ontologies (as stated in Section 3) indicate that all geographical concepts can be mapped as a specialization of one of the four main concepts, shown in Figure 2. These properties indicate that any concept in a geo-ontology $\mathrm{O}_{1}$ either has a similar concept in geo-ontology $\mathrm{O}_{2}$ or has a generalization in $\mathrm{O}_{2}$. In the worst case, a concept in a geo-ontology $\mathrm{O}_{1}$ is mapped to one of the four top-level concepts of the geoontology $\mathrm{O}_{2}$.

\subsection{Using the Results of Matching for Assessing Interoperability}

The results of the Match operator can be used to assess the degree of interoperability between two geo-ontologies. Intuitively, a geo-ontology $\mathrm{O}_{1}$ is interoperable with a geo-ontology $\mathrm{O}_{2}$ when all the information present in $\mathrm{O}_{1}$ (i.e., all of its concepts) can be conveyed in $\mathrm{O}_{2}$. The intuition behind this definition is the basis for the notion of fully interoperable geo-ontologies presented below. Assuming the existence of a Match operator between two geo-ontologies that produces as a result the sets Sim and Gen (see above), we can now define various degrees of interoperability between two geo-ontologies $\mathrm{O}_{1}$ and $\mathrm{O}_{2}$. 
Definition 1. $\mathrm{O}_{1}$ is fully interoperable with $\mathrm{O}_{2}$ iff the similarity subset $\operatorname{Sim}\left(\mathrm{O}_{1}, \mathrm{O}_{2}\right)$ contains all the concepts of $\mathrm{O}_{1}$. This definition matches the intuitive definition of interoperability given in the beginning of this section.

Definition 2. $\mathrm{O}_{1}$ is partially interoperable with $\mathrm{O}_{2}$ iff the generalization subset Gen $\left(\mathrm{O}_{1}, \mathrm{O}_{2}\right)$ is non-empty. In this case, some concepts in $\mathrm{O}_{1}$ are mapped into more general concepts in $\mathrm{O}_{2}$.

Definition 3. Given a non-empty generalization subset $\operatorname{Gen}\left(\mathrm{O}_{1}, \mathrm{O}_{2}\right)$, the degree of interoperability $(d)$ between $\mathrm{O}_{1}$ and $\mathrm{O}_{2}$ is given by the formula

$$
d=f * \frac{\sum_{i=1}^{n} \min \left(l_{2}{ }^{i}, l_{1}^{i}\right)}{\sum_{i=1}^{n} l_{1}^{i}}
$$

where $f$ is the fraction of concepts of $\mathrm{O}_{1}$ that are contained in $\operatorname{Sim}\left(\mathrm{O}_{1}, \mathrm{O}_{2}\right)$, and the second factor estimates the degree of mismatch between the ontologies. In the formula above $l_{1}^{i}$ is the depth of the $\mathrm{i}^{\text {th. }}$ concept of ontology $\mathrm{O}_{1}$ and $l_{2}^{i}$ is the depth of the corresponding concept in ontology $\mathrm{O}_{2}$, as given by the tuples in Gen $\left(\mathrm{O}_{1}, \mathrm{O}_{2}\right)$. The idea is that a discrepancy between the corresponding depth-levels of two related concepts in the Gen $\left(\mathrm{O}_{1}, \mathrm{O}_{2}\right)$ relation is an additional indication of limitations of interoperability between ontologies. The degree of mismatch is obtained by comparing the depth of the tree associated to the concepts in the generalization subset $\operatorname{Gen}\left(\mathrm{O}_{1}, \mathrm{O}_{2}\right)$. The formula is based on the intuitive idea that the greater the difference between the depth levels of the two concepts, the smaller the degree of interoperability between the two geo-ontologies.

To allow an intuitive grasp on our argument, we will illustrate our concepts by considering the problem of land-cover classification. Broadly speaking, land cover is defined as the observed physical cover including the vegetation (natural or planted) and human constructions on the surface of the Earth. Water, ice, bare rock or sand surfaces count as land cover (Jansen \& Gregorio, 2002). The rapidly changing nature of some of our environments (e.g. tropical forests) has motivated a variety of regional and global land cover products, such as the IGBP DisCover, MODIS Land Cover, and GOFC (Global Observation of Forest Cover). As an example of similarity mapping, we consider a subset 
of two existing land cover classification systems: the IGBP Land Cover Classification (Belward, Estes, \& Kline, 1999) and the Simple Biosphere Model (SiB) (P. J. Sellers, Mintz, Sud, \& Dalcher, 1986). This subset deals with forest classes. Each model has 5 forest classes, as shown in Figures 3 and 4.

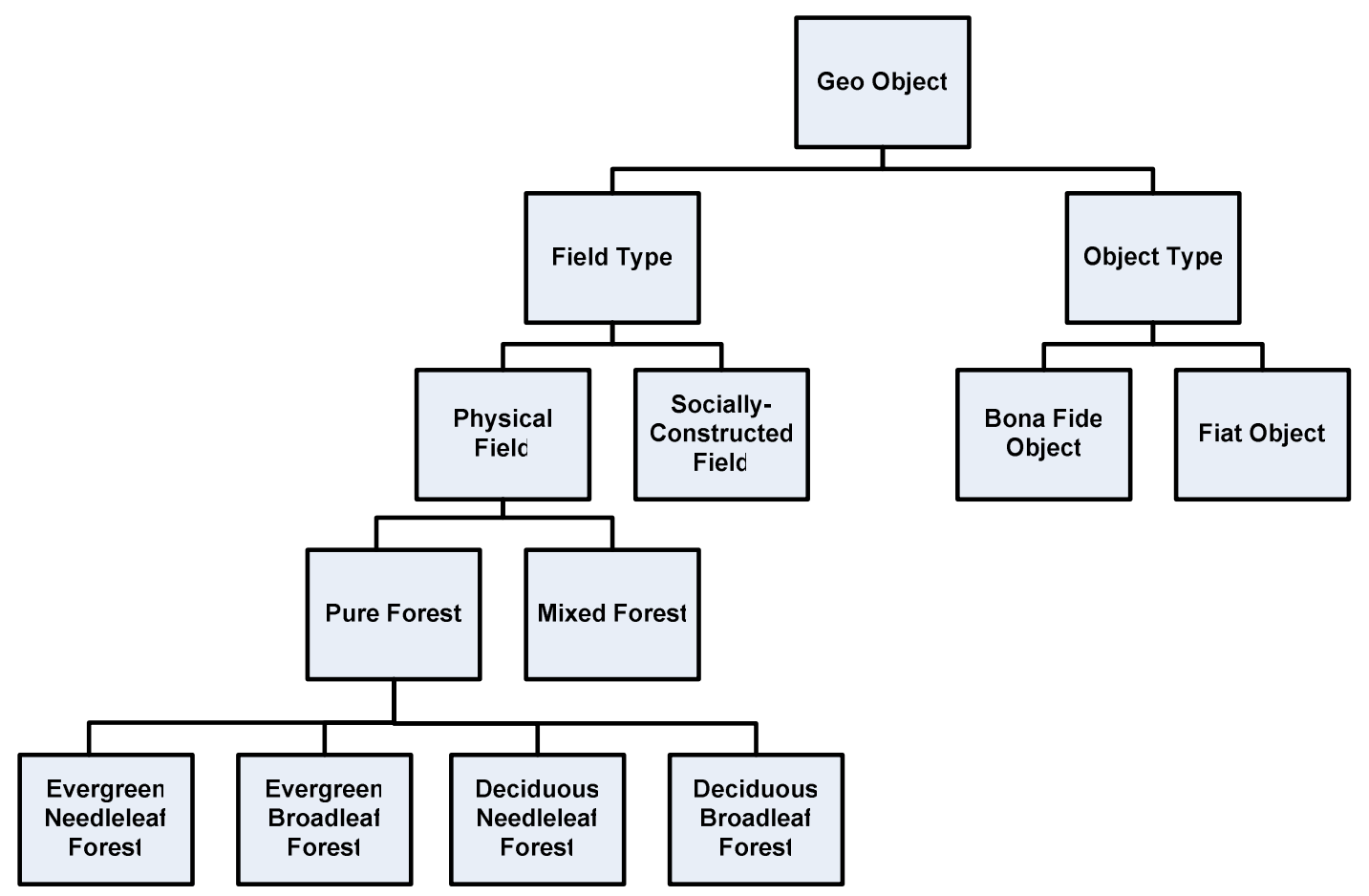

Figure 3 - Forest classification in the IGBP ontology (partial view), adapted from (Belward et al., 1999). 


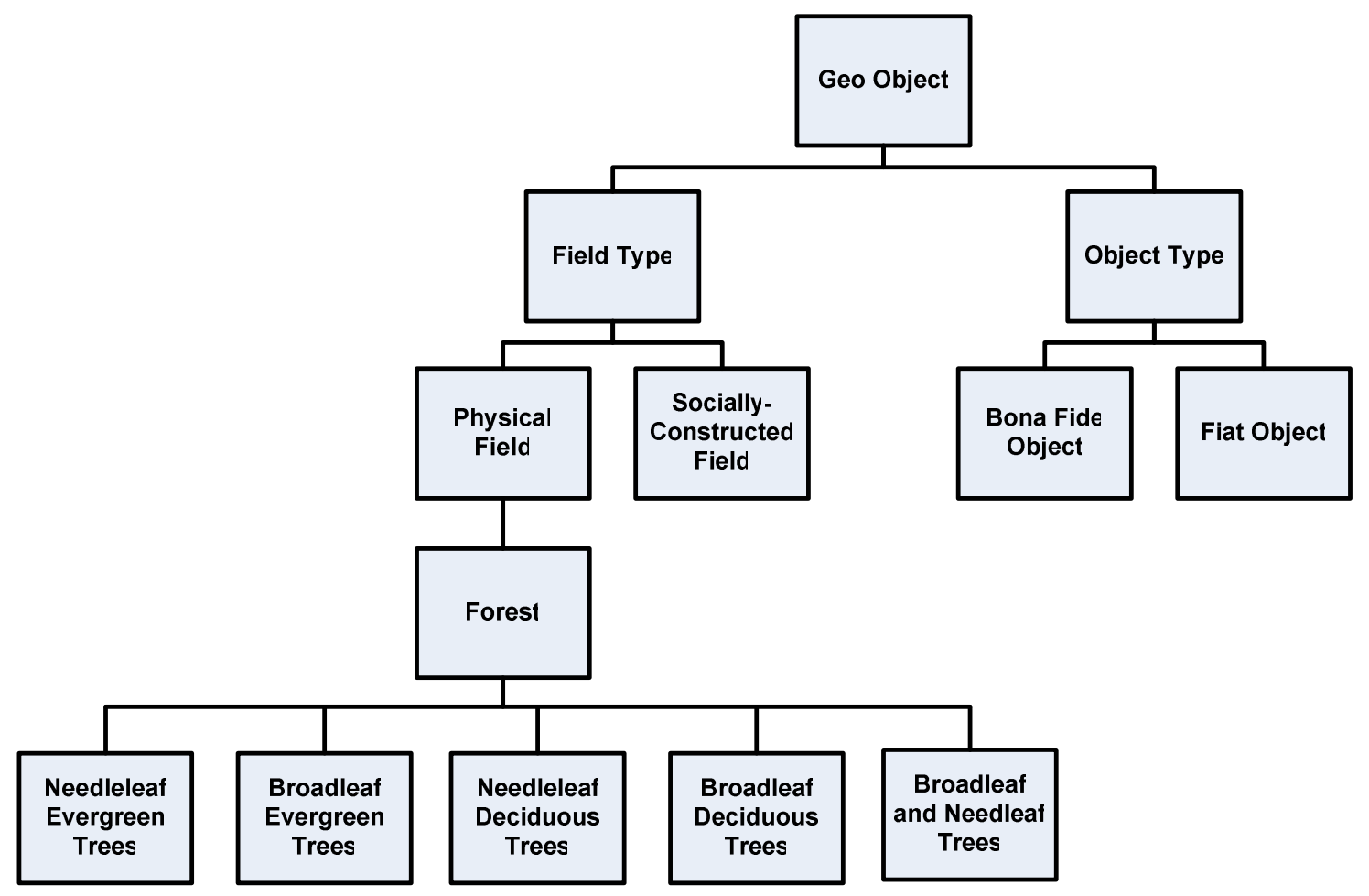

Figure 4 - Forest classification in SiB ontology (partial view), adapted from (P. J. Sellers et al., 1986).

A comparison of the IGBP and $\mathrm{SiB}$ forest classification reveals that the two ontologies are equivalent on their classification of pure forest types. However, they differ when dealing with mixed forest. The IGBP ontology has the concept of "mixed forest" and the $\mathrm{SiB}$ ontology has the concept of "broadleaf and needleleaf trees". Therefore, these two concepts are considered to be similar.

The similarity subset obtained by the Match operator for the IBGP and SiB ontologies for forest is shown in Table 1. All of the concepts associated to forest in the ontology $\mathrm{O}_{2}$ (the IBGP ontology) could be mapped into similar concepts of ontology $\mathrm{O}_{1}$ (the $\mathrm{SiB}$ ontology). This implies that the subsets of these two land-cover ontologies that deal with forest are fully interoperable.

Table 1 - Similarity mapping between IGBP and SiB geo-ontologies for forest land-cover

\begin{tabular}{|l|l|}
\hline \multicolumn{1}{|c|}{ IGBP } & \multicolumn{1}{c|}{ SiB } \\
\hline Evergreen Needleleaf Forest & Needleleaf Evergreen Trees \\
\hline Evergreen Broadleaf Forest & Broadleaf Evergreen Trees \\
\hline Deciduous Needleleaf Forest & Needleleaf Deciduous Trees \\
\hline Deciduous Broadleaf Forest & Broadleaf Deciduous Trees \\
\hline
\end{tabular}


To take a second example, consider the case of the IBGP ontology for forests and the ontology of International Satellite Land Surface Climatology Project (ISLSCP) (P.J. Sellers et al., 1995). The ISLSCP ontology for forests is shown in Figure 5.

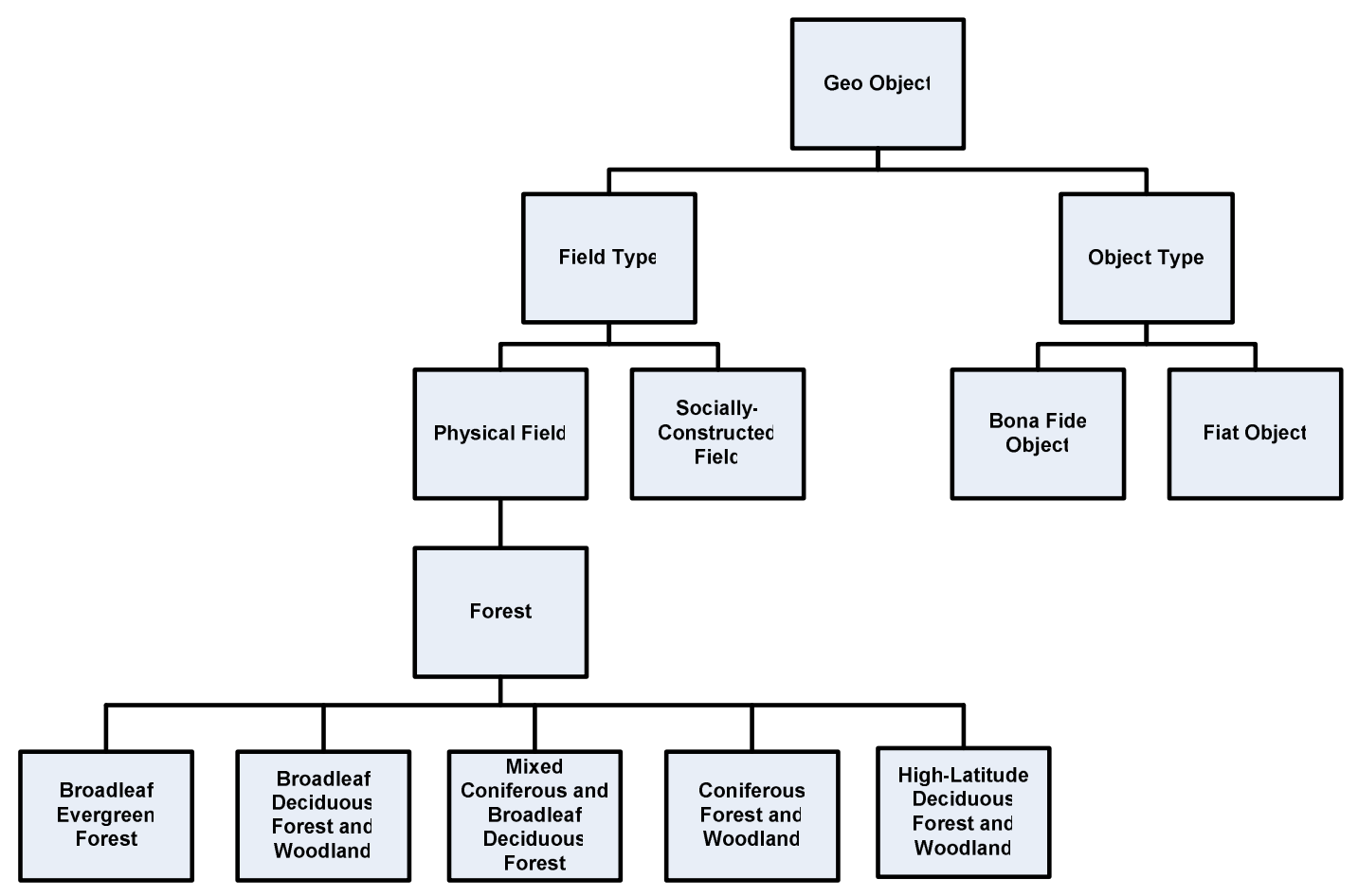

Figure 5 - Forest classification in the ISLSCP ontology (partial view), adapted from (P.J. Sellers et al., 1995).

The ISLSCP ontology is based on a different classification of forest types. This classification includes both pure types ("broadleaf coniferous forest") and mixed specialized types ("mixed coniferous and broadleaf deciduous forest" and "high-latitude deciduous forest and woodland"). This allows the distinction between different types of temperate forests. Thus, the IGBP and ISLSCP ontologies have different objectives, and the latter is more detailed than the former. When matching the concepts of the two ontologies, there is a similarity match between the concepts of "broadleaf evergreen forest" and "broadleaf deciduous forest" of the two ontologies. However, given the differences between the specialized types of temperate forests, there is no similarity match in the IGBP ontology to the three other concepts of the ISLSCP ontology. The two types of pure temperate forests of ISLSCP ontology ("coniferous forest and woodland" and "high- 
latitude decidous forest and woodland") are mapped into the more generic type "pure forest" of the IGBP ontology. The specialized mixed type of the ISLSCP ontology ("mixed coniferous and broadleaf deciduous forest") is mapped to the more generic type "mixed forest" of the IGBP ontology. Thus, the two geo-ontologies of the IGBP and the ISLSCP are not fully interoperable and the result of the Match operator is shown in Table 2.

Table 2 - Matching between the ISLCP and IGBP geo-ontologies for forest land-cover.

\begin{tabular}{|c|c|c|}
\hline ISLSCP & IGBP & Relation \\
\hline $\begin{array}{c}\text { Broadleaf evergreen } \\
\text { forest }\end{array}$ & $\begin{array}{c}\text { Evergreen Broadleaf } \\
\text { Forest }\end{array}$ & Similarity \\
\hline $\begin{array}{c}\text { Broadleaf deciduous } \\
\text { forest and woodland }\end{array}$ & $\begin{array}{c}\text { Deciduous Broadleaf } \\
\text { Forest }\end{array}$ & Similarity \\
\hline $\begin{array}{c}\text { Mixed coniferous and } \\
\text { broadleaf deciduous forest }\end{array}$ & Mixed Forest & Generalization \\
\hline $\begin{array}{c}\text { Coniferous forest and } \\
\text { woodland }\end{array}$ & Pure Forest & Generalization \\
\hline $\begin{array}{c}\text { High latitude deciduous } \\
\text { forest and woodland }\end{array}$ & Pure Forest & \\
\hline
\end{tabular}

Given that there is only a partial relation of interoperability between the ISLSCP and the IGBP geo-ontologies for forests, we can compute the degree of interoperability between them. The similarity subset comprises $60 \%$ of the ontology. The three concepts of ISLSCP that are generalized in the IGBP ontology are placed in level 4 of the ISLSCP tree hierarchy and are mapped to a single concept in level 3 of the IGBP tree hierarchy. This mismatch produces a further decrease on the degree of interoperability of $75 \%$. The degree of interoperability between ISLSCP and IGBP is the product of the fraction of similarity $(60 \%)$ by the degree of mismatch between hierarchies $(75 \%)$ thereby obtaining an estimate of $45 \%$. This example is an illustration of the expressive power of the proposed methodology for assessing the degree of interoperability between two geo-ontologies.

\section{Conclusions and Future Work}

In this paper we studied the problem of interoperability between geo-ontologies. A geoontology describes: (a) things that can be assigned to locations on the surface of the Earth; and (b) semantic and spatial relations between these things. We argued that a geo-ontology has concepts that correspond to physical and social phenomena in the real world. We called 
the first type of concepts physical concepts and the second type, social concepts. We suggested a classification of these concepts based on their type of boundary and based on their physical or social characteristics.

We presented a framework for measuring interoperability between geo-ontologies. We considered that this problem is a special case of Bernstein's (2003) model management algebra for metadata descriptions. We proposed using the Match operator for dealing with interoperability. The Match operator takes two models and returns two sets of tuples that reflect the similarity and generalization relationships that exist between the concepts of the two ontologies.

Based on the Match operator, we defined various degrees of interoperability between two geo-ontologies $\mathrm{O}_{1}$ and $\mathrm{O}_{2}$. Two ontologies can be fully or partially interoperable. We also provided a way to measure to what degree two ontologies are interoperable.

Since we consider that concepts in an ontology are separated from instances in a database, we limited ourselves to discuss only concepts in ontologies. Nonetheless it is important to extend this discussion to the data itself, i.e., the measurements that are linked to the concepts in an ontology. Once we have a measurement of how interoperable two ontologies are, how this will reflect on the interoperability of the datasets that are represented by these ontologies?

Another aspect to be considered is what Goodchild (1997) correctly highlights: what is the information used for? Algebraic approaches as ours and Kuhn's (1997), still have to incorporate a further semantic dimension to information integration and interoperability problems. The philosophical approaches on ontology integration based on hermeneutics (Fonseca \& Martin, 2005) may be a direction to be explored. The concept of the preunderstanding that a user makes of information and its extension to the pre-understanding of a whole community (and its ontology) is very close to the central role of presuppositions, or prejudices, in framing and guiding the emergence of experience in the work of Heideger (1962) and Gadamer (1975). Hence, attempts to develop interoperation frameworks that will satisfy both the formalism proposed by us and Kunh, and the practical and intuitive issues raised by Goodchild will have to deal with a hermeneutic approach to ontologies one compatible with the orientation introduced into information science by Winograd and 
Flores (1986). Recent work emphasizing the importance of interpretation as one of the basic constituents of the information process (Capurro \& Hjørland, 2003) and stressing the importance of hermeneutics in the construction of ontologies (Fonseca \& Martin, 2005) point in a direction that may give some answers to Goodchild's questions.

\section{Acknowledgements}

Frederico Fonseca's work is supported by the National Science Foundation under NSF ITR grant number 0219025, by a fellowship from the National Center for Supercomputing Applications at the University of Illinois, and by funds from Penn State's College of Information Sciences and Technology. Gilberto Camara's work is partially funded by CNPq (grants PQ - 300557/19996-5 and 550250/2005-0) and FAPESP (grant 04/11012-0). The authors also would like to thank the anonymous reviewers for their comments that helped the improvement of the final version of this paper.

\section{References}

Anselin, L. (1989). What is Special About Spatial Data? Alternative Perspectives on Spatial Data Analysis. Santa Barbara, CA: NCGIA.

Arumugam, M., Sheth, A., \& Arpinar, I. B. (2002). Towards p2p semantic web: A distributed environment for sharing semantic knowledge on the web. Paper presented at the Workshop on Real World RDF and Semantic Web Applications.

Belward, A. S., Estes, J. E., \& Kline, K. D. (1999). The IGBP-DIS 1-Km Land-Cover Data Set DISCover: A Project Overview. Photogrammetric Engineering and Remote Sensing, 65(9), 1013-1020.

Bench-Capon, T., \& Malcolm, G. (1999). Formalising Ontologies and Their Relations. In Lecture Notes in Computer Science (Vol. 1677).

Bench-Capon, T., Malcolm, G., \& Shave, M. (2003). Semantics for interoperability: relating ontologies and schemata. Paper presented at the Database and Expert Systems Applications, 14th International Conference, DEXA 2003, Prague, Czech Republic.

Bennett, B. (2001). A categorical axiomatisation of region-based geometry. Fundamenta Informaticae, 36(1-2), 145-158. 
Bergamaschi, S., Castano, S., Vermercati, S., Montanari, S., \& Vincini, M. (1998). An Intelligent Approach to Information Integration. In N. Guarino (Ed.), Formal Ontology in Information Systems (pp. 253-268). Amsterdan, Netherlands: IOS Press.

Berners-Lee, T., Hendler, J., \& Lassila, O. (2001). The Semantic Web: A New Form of Web Content That Is Meaningful To Computers Will Unleash A Revolution Of New Possibilities. The Scientific American, 284(5), 34-43.

Bernstein, P. (2003). Applying Model Management to Classical Meta Data Problems. Paper presented at the Conference on Innovative Database Research, Asilomar, CA.

Bernstein, P. A. (2001). Generic Model Management: A Database Infrastructure for Schema Manipulation. Paper presented at the Cooperative Information Systems, 9th International Conference, CoopIS 2001, Trento, Italy.

Bishr, Y. (1997). Semantic Aspects of Interoperable GIS. Unpublished Ph.D. Thesis, Wageningen Agricultural University, The Netherlands.

Bishr, Y. A., \& Kuhn, W. (2000). Ontology-Based Modelling of Geospatial Information. Paper presented at the 3rd. AGILE Conference on Geographic Information Science, Helsink, Finland.

Bittner, T., \& Winter, S. (1999). On Ontology in Image Analysis in Integrated Spatial Databases. In P. Agouris \& A. Stefanidis (Eds.), Integrated Spatial Databases: Digital Images and GIS - Lecture Notes in Computer Science (Vol. 1737, pp. 168-191). Berlin: Springer Verlag.

Câmara, G., Monteiro, A., Paiva, J., \& Souza, R. (2000). Action-Driven Ontologies of the Geographical Space: Beyond the Field-Object Debate. Paper presented at the GIScience 2000-First International Conference on Geographic Information Science, Savannah, GA.

Câmara, G., Souza, R., Freitas, U., \& Monteiro, A. (1999). Interoperability in Practice: Problems in Semantic Conversion from Current Technology to OpenGIS. In A. Vckovski, K. Brassel \& H.-J. Schek (Eds.), Interoperating Geographic Information Systems - Second International Conference, INTEROP'99 (Vol. 1580, pp. 129-138). Berlin: Springer-Verlag.

Capurro, R., \& Hjørland, B. (2003). The Concept of Information. Annual Review of Information Science \& Technology, 37(8), 343-411. 
Casati, R., \& Varzi, A. (1999). Parts and Places. Cambridge, MA: MIT Press.

Chandrasekaran, B., Josephson, J. R., \& Benjamins, V. R. (1999). What Are Ontologies? Why Do We Need Them? IEEE Intelligent Systems, 14(1), 20-26.

Chrisman, N. (1999). A Transformational Approach to GIS Operations. International Journal of Geographical Information Science, 13(7), 617-637.

Couclelis, H. (1992). People Manipulate Objects (but Cultivate Fields): Beyond the Raster-Vector Debate in GIS. In A. U. Frank, I. Campari \& U. Formentini (Eds.), Theories and Methods of Spatio-Temporal Reasoning in Geographic Space (Vol. 639, pp. 65-77). New York: Springer-Verlag.

Egenhofer, M. (1993). What's Special about Spatial?-Database Requirements for Vehicle Navigation in Geographic Space. SIGMOD RECORD, 22(2), 398-402.

Farquhar, A., Fikes, R., \& Rice, J. (1996). The Ontolingua Server: A Tool for Collaborative Ontology Construction (Technical Report No. KSL 96-26). Stanford, CA: Knowledge Systems Laboratory, Stanford University.

Fonseca, F., \& Egenhofer, M. (1999). Ontology-Driven Geographic Information Systems. Paper presented at the 7th ACM Symposium on Advances in Geographic Information Systems, Kansas City, MO.

Fonseca, F., Egenhofer, M., Agouris, P., \& Câmara, G. (2002). Using Ontologies for Integrated Geographic Information Systems. Transactions in GIS, 6(3), 231-257.

Fonseca, F., Egenhofer, M., Davis, C., \& Câmara, G. (2002). Semantic Granularity in Ontology-Driven Geographic Information Systems. AMAI Annals of Mathematics and Artificial Intelligence - Special Issue on Spatial and Temporal Granularity, 36(1-2), 121151.

Fonseca, F., \& Martin, J. (2004). Space and Time in Eco-Ontologies. AI Communications - The European Journal on Artificial Intelligence, 17(4), 259-269.

Fonseca, F., \& Martin, J. (2005). Toward an Alternative Notion of Information Systems Ontologies: Information Engineering as a Hermeneutic Enterprise. Journal of the American Society for Information Science and Technology, 56(1), 46-57. 
Frank, A. (1997). Spatial Ontology. In O. Stock (Ed.), Spatial and Temporal Reasoning (pp. 135-153). Dordrecht, The Netherlands: Kluwer Academic.

Frank, A. (2001). Tiers of Ontology and Consistency Constraints in Geographical Information Systems. International Journal of Geographical Information Science, 15(7), 667-678.

Frank, A., \& Mark, D. (1991). Language Issues for GIS. In D. Maguire, M. Goodchild \& D. Rhind (Eds.), Geographical Information Systems, Volume 1: Principles (pp. 147163). London: Longman.

Frank, A., \& Raubal, M. (1999). Formal Specification of Image Schemata-a Step towards Interoperability in Geographic Information Systems. Spatial Cognition and Computation, 1(1), 67-101.

Gadamer, H.-G. (1975). Truth and Method (J. Weinsheimer \& D. G. Marshall, Trans.). New York: Seabury Press.

Gahegan, M. (1999). Characterizing the Semantic Content of Geographic Data, Models, and Systems. In M. Goodchild, M. Egenhofer, R. Fegeas \& C. Kottman (Eds.), Interoperating Geographic Information Systems (pp. 71-84). Norwell, MA: Kluwer Academic.

Goodchild, M. (1992). Geographical Data Modeling. Computers and Geosciences, 18(4), 401-408.

Goodchild, M. (1997). Algebra and Information Loss: a Response to Kuhn. Geographical Systems, 4(3), 277-280.

Goodchild, M., Egenhofer, M., Fegeas, R., \& Kottman, C. (1999). Interoperating Geographic Information Systems. Norwell, MA: Kluwer Academic.

Gruber, T. (1992). A Translation Approach to Portable Ontology Specifications (Technical Report No. KSL 92-71). Stanford, CA: Knowledge Systems Laboratory, Stanford University.

Guarino, N. (1998). Formal Ontology and Information Systems. In N. Guarino (Ed.), Formal Ontology in Information Systems (pp. 3-15). Amsterdam, Netherlands: IOS Press. 
Harvey, F. (1999). Designing for Interoperability: Overcoming Semantic Differences. In M. Goodchild, M. Egenhofer, R. Fegeas \& C. Kottman (Eds.), Interoperating Geographic Information Systems (pp. 85-98). Norwell, MA: Kluwer Academic.

Heflin, J., \& Hendler, J. A. (2000). Dynamic Ontologies on the Web. Paper presented at the The Seventeenth National Conference on Artificial Intelligence and Twelfth Conference on on Innovative Applications of Artificial Intelligence, Austin, TX.

Heidegger, M. (1962). Being and Time (J. Macquarrie \& E. Robinson, Trans.). New York: Harper.

Husserl, E. (1970). Logical investigations (1st German Edition 1900 ed.). London New York: Routledge and K. Paul - Humanities Press.

Jansen, L. J. M., \& Gregorio, A. D. (2002). Parametric land cover and land-use classifications as tools for environmental change detection. Agriculture Ecosystems and Environmen, 91(89-100).

Kalfoglou, Y., \& Schorlemmer, M. (2003). Ontology mapping: the state of the art. The Knowledge Engineering Review, 18(1), 1-31.

Kashyap, V., \& Sheth, A. (1996). Semantic Heterogeneity in Global Information System: The Role of Metadata, Context and Ontologies. In M. Papazoglou \& G. Schlageter (Eds.), Cooperative Information Systems: Current Trends and Directions (pp. 139-178). London: Academic Press.

Kavouras, M., \& Kokla, M. (2002). A method for the formalization and integration of geographical categorizations. International Journal of Geographical Information Science, $16(5), 439-453$.

Kavouras, M., Kokla, M., \& Tomai, E. (2005). Comparing categories among geographic ontologies. Computers \& Geosciences, 31(2), 145-154.

Kent, W. (1993). Object Orientation and Interoperability. In Advances in ObjectOriented Database Systems (Vol. 130, pp. 287-305). Izmir, Kusadasi, Turkey: Springer.

Kuhn, W. (1994). Defining Semantics for Spatial Data Transfer. Paper presented at the Sixth International Symposium on Spatial Data Handling, Edinburgh, Scotland. 
Kuhn, W. (1997). Approaching the Issue of Information Loss in Geographic Data Transfers. Geographical Systems, 4(3), 261-276.

Kuhn, W. (2001). Ontologies in Support of Activities in Geographical Space. International Journal of Geographical Information Science, 15(7), 613-631.

Kuhn, W. (2003). Semantic Reference Systems. International Journal of Geographic Information Science, 17(5), 405-409.

Mark, D. (1993). Toward a Theoretical Framework for Geographic Entity Types. In A. Frank \& I. Campari (Eds.), Spatial Information Theory (Vol. 716, pp. 270-283). Berlin: Springer-Verlag.

Mark, D., \& Egenhofer, M. (1994). Calibrating the Meanings of Spatial Predicates from Natural Language: Line-Region Relations. Paper presented at the Sixth International Symposium on Spatial Data Handling, Edinburgh, Scotland.

Mark, D., Smith, B., \& Tversky, B. (1999). Ontology and Geographic Objects: An Empirical Study of Cognitive Category. In C. Freksa \& D. Mark (Eds.), Spatial Information Theory-Cognitive and Computational Foundations of Geographic Information Science, COSIT '99, Stade, Germany (Vol. Lecture Notes in Computer Science V. 1661, pp. 283298). Berlin: Springer-Verlag.

McGuinness, D. L. (2003). Ontologies Come of Age. In D. Fensel, W. Wahlster, H. Lieberman \& J. Hendler (Eds.), Spinning the semantic Web: bringing the World Wide Web to its full potential (pp. xxiii, 479). Cambridge, Mass.: MIT Press.

Mena, E., Kashyap, V., Illarramendi, A., \& Sheth, A. (1998). Domain Specific Ontologies for Semantic Information Brokering on the Global Information Infrastructure. In N. Guarino (Ed.), Formal Ontology in Information Systems (pp. 269-283). Amsterdam: IOS Press.

Mena, E., Kashyap, V., Sheth, A., \& Illarramendi, A. (1996). OBSERVER: An Approach for Query Processing in Global Information Systems based on Interoperation across Pre-existing Ontologies. Paper presented at the First IFCIS International Conference on Cooperative Information Systems (CoopIS'96), Brussels, Belgium. 
Noy, N. F. (2004). Semantic integration: a survey of ontology-based approaches. ACM SIGMOD Record, 33(4), 65-70.

Noy, N. F., \& Musen, A. M. (2002). Evaluating Ontology-Mapping Tools: Requirements and Experience. Paper presented at the OntoWeb-SIG3 Workshop at the 13th International Conference on Knowledge Engineering and Knowledge Management, Siguenza, Spain.

OpenGIS. (1996). The OpenGIS ${ }^{\circledR}$ Guide-Introduction to Interoperable Geoprocessing and the OpenGIS Specification. Wayland, MA: Open GIS Consortium, Inc.

Papakonstantinou, Y., Garcia-Molina, H., \& Widom, J. (1995, march 1995). Object Exchange Across Heterogeneous Information Sources. Paper presented at the IEEE International Conference on Data Engineering, Taipei, Taiwan.

Preece, A., Hui, K., Gray, A., Marti, P., Bench-Capon, T., Jones, D., et al. (2000). The KRAFT architecture for knowledge fusion and transformation. Knowledge-Based Systems, 12(2-3), 113-120.

Raubal, M., \& Kuhn, W. (2004). Ontology-Based Task Simulation. Spatial Cognition and Computation, 4(1), 15-38.

Rodríguez, A., \& Egenhofer, M. (2003). Comparing Geospatial Entity Classes: An Asymmetric and Context-Dependent Similarity Measure. International Journal of Geographical Information Science, 18(3), 229-256.

Rodríguez, A., \& Egenhofer, M. (2003). Determining Semantic Similarity Among Entity Classes from Different Ontologies. IEEE Transactions on Knowledge and Data Engineering, 15(2), 442-456.

Rodríguez, A., Egenhofer, M., \& Rugg, R. (1999). Assessing Semantic Similarity Among Geospatial Feature Class Definitions. In A. Vckovski, K. Brassel \& H.-J. Schek (Eds.), Interoperating Geographic Information Systems-Second International Conference, INTEROP'99 (Vol. 1580, pp. 1-16). Berlin: Springer-Verlag.

Searle, J. (1995). The Construction of Social Reality. New York: The Free Press. 
Sellers, P. J., Meeson, B. W., Hall, F. G., Asrar, G., Murphy, R. E., Schiffer, R. A., et al. (1995). Remote sensing of the land surface for studies of global change: Models algorithms - experiments. Remote Sensing of Environment, 51(1), 3-26.

Sellers, P. J., Mintz, Y., Sud, Y. C., \& Dalcher, A. (1986). A Simple Biosphere Model $(\mathrm{SiB})$ for Use within General Circulation Models. Journal of the Atmospheric Sciences, 43(6), 505-531.

Sheth, A. (1999). Changing Focus on Interoperability in Information Systems: from System, Syntax, structure to Semantics. In M. Goodchild, M. Egenhofer, R. Fegeas \& C. Kottman (Eds.), Interoperating Geographic Information Systems (pp. 5-29). Norwell, MA: Kluwer Academic.

Sheth, A., \& Larson, J. (1990). Federated Databases Systems for Managing Distributed, Heterogeneous, and Autonomous Databases. ACM Computing Surveys, 22(3), 183-236.

Simons, P. (1987). Parts: An Essay in Ontology. Oxford: Clarendon Press.

Smith, B. (1995). On Drawing Lines on a Map. In A. Frank \& W. Kuhn (Eds.), Spatial Information Theory-A Theoretical Basis for GIS, International Conference COSIT '95 (Vol. 988, pp. 475-484). Berlin: Springer Verlag.

Smith, B. (2003). Ontology. In L. Floridi (Ed.), The Blackwell Guide to the Philosophy of Computing and Information (pp. 155-166). Malden, MA: Blackwell.

Smith, B., \& Mark, D. (1998). Ontology and Geographic Kinds. Paper presented at the International Symposium on Spatial Data Handling, Vancouver, BC, Canada.

Smith, B., \& Mark, D. (2003). Do Mountains Exist? Towards an Ontology of Landforms. Environment and Planning B: Planning and Design, 30(3), 411-427.

Smith, B., \& Searle, J. (2003). The construction of social reality: an exchange. The American Journal of Economics and Sociology, 62(1), 283-309.

Vckovski, A. (1998). International Journal of Geographical Information Science Special Issue: Interoperability in GIS. 12(4), 297-298. 
Wache, H. (1999). Towards rule-based context transformation in mediators. Paper presented at the International Workshop on Engineering Federated Information Systems (EFIS 99), Kuhlungsborn, Germany.

Wache, H., Voegele, T., Visser, U., Stuckenschmidt, H., Schuster, G., Neumann, H., et al. (2001). Ontology-based integration of information - a survey of existing approaches. Paper presented at the IJCAI-01 Workshop on Ontologies and Information Sharing, Seattle, WA.

Wiederhold, G. (1991). Mediators in the Architecture of Future Information Systems: Stanford University.

Wiederhold, G. (1994). Interoperation, Mediation and Ontologies. Paper presented at the International Symposium on Fifth Generation Computer Systems (FGCS94), Tokyo, Japan.

Winograd, T., \& Flores, F. (1986). Understanding Computers and Cognition: a New Foundation for Design. Norwood, N.J.: Ablex Pub. Corp.

Worboys, M., \& Deen, S. (1991). Semantic Heterogeneity in Geographic Databases. SIGMOD RECORD, 20(4), 30-34. 